\title{
EXISTENCE AND UNIQUENESS FOR DOUBLY NONLINEAR PARABOLIC EQUATIONS WITH NONSTANDARD GROWTH CONDITIONS
}

\section{Stanislav AntontseV and Sergey ShmareV}

Abstract. We study the homogeneous Dirichlet problem for the equation

$$
u_{t}=\sum_{i=1}^{n} D_{i}\left(a_{i}\left|D_{i}\left(|u|^{m(x)-1} u\right)\right|^{p_{i}(x, t)-2} D_{i}\left(|u|^{m(x)-1} u\right)\right)+b|u|^{\sigma(x, t)-2} u
$$

with given exponents $m(x), p_{i}(x, t)$ and $\sigma(x, t)$. It is proved that the problem has a solution in a suitable variable exponent Sobolev space. In dependence on the properties of the coefficient $b$ and the exponents of nonlinearity, the solution exists globally or locally in time. The comparison principle and uniqueness are proved under additional restrictions on the data.

Mathematics subject classification (2010): 35K55, 35K65, 35K67, 35K92.

Keywords and phrases: nonlinear parabolic equations, double nonlinearity, nonstandard growth conditions.

\section{REFERENCES}

[1] S. Antontsev, M. Chipot, AND S. Shmarev, Uniqueness and comparison theorems for solutions of doubly nonlinear parabolic equations with nonstandard growth conditions, to appear in Commun. Pure Appl. Anal.

[2] S. N. Antontsev, J. I. Díaz, And S. Shmarev, Energy methods for free boundary problems. Applications to nonlinear PDEs and fluid mechanics, Progress in Nonlinear Differential Equations and their Applications, 48, Birkhäuser Boston, Inc., Boston, MA, 2002.

[3] S. N. Antontsev And S. I. Shmarev, Parabolic equations with anisotropic nonstandard growth conditions, Free boundary problems, 33-44, Internat. Ser. Numer. Math., 154, Birkhäuser, Basel, 2007.

[4] S. N. ANTONTSEV AND S. I. SHMAREV, Anisotropic parabolic equations with variable nonlinearity, Publ. Mat., 53, 2 (2009), 355-399.

[5] S. N. ANTONTSEV AND S. I. SHMAREV, Localization of solutions of anisotropic parabolic equations, Nonlinear Anal., 71, 12 (2009), 725-737.

[6] S. N. Antontsev And S. I. Shmarev, Blow-up of solutions to parabolic equations with nonstandard growth conditions, J. Comput. Appl. Math., 234, 9 (2010), 2633-2645.

[7] S. N. AntontSEV AND S. I. Shmarev, On the blow-up of solutions to anisotropic parabolic equations with variable nonlinearity, Proc. Steklov Inst. Math., 270, 1 (2010), $27-42$.

[8] S. N. ANTONTSEV AND S. I. Shmarev, Vanishing solutions of anisotropic parabolic equations with variable nonlinearity, J. Math. Anal. Appl., 361, 2 (2010), 371-391.

[9] S. N. Antontsev And S. I. Shmarev, Parabolic equations with double variable nonlinearities, Math. Comput. Simulation, 81, 10 (2011), 2018-2032.

[10] S. N. Antontsev and S. I. Shmarev, Elliptic equations with triple variable nonlinearity, Complex Var. Elliptic Equ., 56, 7-9 (2011), 573-597.

[11] F. BERNIS, Existence results for doubly nonlinear higher order parabolic equations on unbounded domains, Math. Ann., 279, 3 (1988), 373-394.

[12] C. CHEN, Global existence and $L^{\infty}$ estimates of solution for doubly nonlinear parabolic equation, J. Math. Anal. Appl., 244, 1 (2000), 133-146. 
[13] M. ChIPOT AND J.-F. Rodrigues, Comparison and stability of solutions to a class of quasilinear parabolic problems, Proc. Roy. Soc. Edinburgh Sect. A, 110, 3-4 (1988), 275-285.

[14] P. Cianci, A. V. Martynenko, And A. F. Tedeev, The blow-up phenomenon for degenerate parabolic equations with variable coefficients and nonlinear source, Nonlinear Anal., 73, 7 (2010), 2310-2323.

[15] S. P. Degtyarev And A. F. Tedeev, Estimates for the solution of the Cauchy problem with increasing initial data for a parabolic equation with anisotropic degeneration and double nonlinearity, Dokl. Math., 76, 3 (2007), 824-827.

[16] J. DíAZ AND J. PADIAL, Uniqueness and existence of a solution in $B V_{t}(q)$ space to a doubly nonlinear parabolic problem, Publ. Mat., 40, 2 (1996), 527-560.

[17] J. DíAZ AND F. THÉLIN, On a nonlinear parabolic problem arising in some models related to turbulent flows, SIAM J. Math. Anal., 25, 4 (1994), 1085-1111.

[18] L. Diening, P. HaRJulehto, P. Hästö, And M. RuŽIČKa, Lebesgue and Sobolev Spaces with Variable Exponents, Springer, Berlin, 2011.

[19] D. E. Edmunds AND J. RÁKosník, Density of smooth functions in $W^{k, p(x)}(\Omega)$, Proc. Roy. Soc. London Ser. A, 437 (1992), 229-236.

[20] K. IsHIGE, On the existence of solutions of the Cauchy problem for a doubly nonlinear parabolic equation, SIAM J. Math. Anal., 27, 5 (1996), 1235-1260.

[21] P. A. Hëstö, On the density of continuous functions in variable exponent Sobolev space, Rev. Mat. Iberoam., 23, 1 (2007), 213-234.

[22] G. I. LAPTEV, Solvability of second-order quasilinear parabolic equations with double degeneration, Siberian Math. J., 38, 6 (1997), 1160-1177.

[23] J.-L. Lions, Quelques méthodes de résolution des problèmes aux limites non linéaires, Dunod, 1969.

[24] S. S Amко, On a progress in the theory of Lebesgue spaces with variable exponent: maximal and singular operators, Integral Transforms Spec. Funct., 16, 5-6 (2005), 461-482.

[25] M. SANGO, On a doubly degenerate quasilinear anisotropic parabolic equation, Analysis (Munich), 23, 3 (2003), 249-260.

[26] J. Simon, Compact sets in the space $L^{p}(0, t ; B)$, Ann. Mat. Pura Appl., 146, 4 (1987), 65-96.

[27] A. F. TEDEEV, The interface blow-up phenomenon and local estimates for doubly degenerate parabolic equations, Appl. Anal., 86, 6 (2007), 755-782.

[28] V. V. Zhikov, On the density of smooth functions in Sobolev-Orlicz spaces, J. Math. Sci. (N. Y.), 132, 3 (2006), 285-294.

[29] V. V. Zhikov And S. E. Pastukhova, Lemmas on compensated compactness in elliptic and parabolic equations, Proc. Steklov Inst. Math., 270, 1 (2010), 104-131. 